\title{
Immunohistochemical assessment of Fhit protein expression in advanced gastric carcinomas in correlation with Helicobacter pylori infection and survival time
}

\author{
Jolanta Czyżewska1, Katarzyna Guzińska-Ustymowicz², Anna Pryczynicz², \\ Andrzej Kemona ${ }^{2}$ and Roman Bandurski ${ }^{3}$. \\ ${ }^{1}$ Department of Clinical Laboratory Diagnostics \\ 2Department of General Pathomorphology \\ ${ }^{3} I^{\text {nd }}$ Department of General and Gastroenterological Surgery, Medical University of Białystok, \\ Białystok, Poland
}

\begin{abstract}
Fhit protein is known to play a role in the process of neoplastic transformation. It has been demonstrated that FHIT gene inactivation is manifested by a lack or very low concentration of Fhit protein in tissues collected from tumours in many organs, including head, neck, breast, lungs, stomach or large intestine. The study included a group of 80 patients with advanced gastric carcinomas. The expression of Fhit protein was assessed by means of the immunohistochemical method (avidin-biotin-streptavidin) in the sections fixed in formalin and embedded in paraffin, using rabbit polyclonal antiFhit antibody (Abcam, UK) at 1: 200. Statistical analysis did not show any correlation of the expression of Fhit protein in the main mass of tumour and in the metastasis to lymph node with gender, depth of wall invasion, histological differentiation, Lauren's classification, Bormann's classification, metastases to local lymph nodes or Helicobacter pylori infection. However, a strong statistical correlation was revealed of Fhit protein expression in the main mass of tumour with patients' age $(p=0.04)$ and tumour location in the stomach $(p=0.02)$. No relationship was found between Fhit expression in the main mass of tumour and survival time $(\mathrm{p}=0.26)$.
\end{abstract}

Key words: gastric carcinoma, Fhit protein

\section{Introduction}

Gastric carcinoma remains one of the most common causes of deaths due to malignant neoplasms worldwide. A rapid increase in the incidence and death rates caused by this carcinoma was recorded in the second half of the $20^{\text {th }}$ century. Gastric carcinoma is the second, after lung cancer, cause of deaths due to malignancies in the world. Its incidence varies geographically, being the highest in Japan, China, South America and much lower in Western Europe and in the USA [1]. Poland is amongst the countries with the highest incidence and mortality rates for this carcinoma. In men, lung cancer is the predominant malignancy,

Correspondence: J. Czyżewska, Department of Clinical Laboratory Diagnostics, Medical University of Białystok,

- Waszyngtona Str. 15a 15-269 Białystok, Poland; tel.: (+4885) 7485942, fax.: (+4885) 7485990,

e-mail: czyzyk15@op.pl being the cause of one third of all carcinomas and deaths due to them. In Poland, like worldwide, gastric carcinoma, is the second cause of deaths due to malignancy among men. Women most frequently die of cancers of the breast, lung, large intestine, ovary and cervix. Gastric carcinoma is the fifth cause of death in women [2].

The vast majority of diagnosed and treated gastric carcinomas are advanced. The lesions surpass the mucous membrane, invade successive layers of the gastric wall, and even infiltrate adjacent organs, giving metastases to local lymph nodes and distant organs.

Gastric carcinogenesis is a complex multistep process resulting from the interaction between genome and environmental factors. Many exogenous factors seem to contribute to the initiation of carcinogenesis in the stomach, including diet, chemical agents and infections, e.g. caused by Helicobacter pylori and EpsteinBarr virus [3]. 
The risk of gastric carcinoma has been shown to increase seven-fold in patients with $H$. pylori infection as compared to non-infected patients. H. pylori exerts its carcinogenic effect in the stomach via one of two possible mechanisms:

1. direct transformation of gastric mucosa via metabolic products,

2. rapid transformation of epithelial cells triggered by infection-induced mucosal damage, which may increase the risk of DNA destruction, thus predisposing the mucosa to transformation through absorption or endogenous mutagens and inflammatory bioproducts, e.g. peroxide and hydroxy ions [4].

The analysis of a tumour suppressor gene, i.a. FHIT gene, and Fhit protein may help in the search of factors responsible for the progression of the neoplastic process.

The FHIT gene is located within the short arm of chromosome 3 (3q14.2) in FRAB3, being the most fragile site in the human genome [5]. The FHIT gene encodes a $16.8 \mathrm{kDa}$ protein. The Fhit protein belongs to the family of Hit proteins (histidine triad), most commonly encountered in nature, both in procaryotic and eucaryotic organisms [6]. The FHIT gene overexpression in several cell lines leads to apoptosis induction and proliferation inhibition [7], thus suggesting that the FHIT gene may play a role in the regulation of cell cycle. In humans, the FHIT gene undergoes inactivation in the early phase of many malignancies, which is usually reflected by loss of heterozygosity, whereas point mutations of the FHIT gene are very rare [8]. Hypermethylation of the promotor region is another mechanism involved in tumour suppressor gene inactivation and has been observed in e.g. gastric carcinoma [9].

The objective of the current study was to assess Fhit protein expression in the main tumour mass and lymph node involvement in advanced gastric carcinoma in correlation with chosen clinicopathological factors, Helicobacter pylori infection and survival time of patients following tumour resection.

\section{Materials and methods}

Patients. The study was performed on a group of 80 patients $(26$ women, 54 men), who were surgically treated for advanced gastric carcinoma in II Department of General Surgery and Gastroenterology, Medical University of Białystok, in the years 1998-2003.

Immunohistochemistry. Formalin-fixed and paraffin-embedded tissue samples were cut on a microtome to obtain $5 \mu \mathrm{m}$ thick sections, which were then deparaffinized in xylenes and rehydrated through decreasing ethanol concentrations. In order to expose the antigen, the sections were heated in a pressure cooker in citrate buffer for $3 \mathrm{~min}(\mathrm{pH}=6.0)$. Next, they were incubated with $3 \%$ hydrogen peroxide followed by incubation with a rabbit polyclonal antiFhit antibody (Abcam, UK) at 1:200 for 60 minutes at room temperature. After reaction in LSAB (LSAB +System HRP, Dako, Poland), the antigen-antibody complex was visualized using chromogene DAB (S3000, DAKO, Poland).
Evaluation of samples. Fhit protein expression was evaluated semiquantitatively and classified as follows:

- 0 - lack of Fhit protein expression in the main mass of tumour and in metastatic lymph node

- 1 - Fhit expression in $1-30 \%$ of the cells assessed in primary tumour and in metastatic lymph node

- 2 - Fhit protein expression in above $30 \%$ of assessed neoplastic cells.

Statistical analysis. Statistical analysis was performed based on the $\chi^{2}$ test and exact Fisher's test. The value of $p<0.05$ was considered statistically significant. Cox analysis was used to determine the correlation between Fhit protein expression and survival time of patients.

\section{Results}

Statistical analysis showed no correlation of Fhit protein expression with patients' gender, depth of invasion, histological differentiation grade or local lymph node involvement. Moreover, no relationship was found between positive immunohistochemical reaction to Fhit protein and patients' age or tumour location in the stomach (Table 1). The findings revealed lack of correlation between the expression of Fhit protein in the metastatic lymph node and the anatomopathological parameters studied (Table 2). Similarly, no statistically significant correlation was noted between the expression of Fhit protein in the main mass of tumour and in the metastatic lymph node (Table 3 ).

No correlation was found between Fhit protein expression and survival time. Patients without Fhit expression or with expression up to $30 \%$ were found to survive approximately 60 months after surgery, whereas survival rate in the case of tumour Fhit expression above $30 \%$ was about 85 months following surgery. The difference was not statistically significant $(\mathrm{p}=0.26)$ (Fig. 1).

\section{Discussion}

Neoplastic transformation is a complex multistep process involving, among others, loss of suppressor gene functions and oncogene activation. These changes affect a number of cellular processes: proliferation, genetic stability or cell survival [10].

The short arm of chromosome 3 is one of the most common sites of chromosomal abnormalities in carcinoma. Loss of chromosome $3 p$ alleles has been described in numerous malignancies, e.g. in the carcinoma of the kidney, lungs and breast [4,11]. The human FHIT gene is located at the FRA3B site of chromosome 3p14.2. The Fhit protein encoded by this gene is able to prevent uncontrolled cell proliferation through a proapoptotic action and inhibition of cell proliferation. Loss of gene FHIT expression may have a pivotal role in the pathogenesis of gastric disorders $[10,12]$. 
Table 1. Correlation between Fhit protein expression in the main mass of tumour and chosen clinicopathological parameters in gastric carcinoma.

\begin{tabular}{|c|c|c|c|c|c|}
\hline \multirow{2}{*}{\multicolumn{2}{|c|}{ Parameters }} & \multicolumn{4}{|c|}{ Expression of Fhit protein in tumor } \\
\hline & & \multirow{2}{*}{$\begin{array}{c}0(n=35) \\
15(42.86 \%)\end{array}$} & \multirow{2}{*}{$\frac{1(\mathrm{n}=21)}{10(47.62 \%)}$} & \multirow{2}{*}{$\begin{array}{c}2(n=24) \\
4(16.67 \%)\end{array}$} & \multirow{2}{*}{$\frac{\mathrm{p}}{0.04}$} \\
\hline$\Lambda \mathrm{ge}$ & $<=60$ & & & & \\
\hline & $>60$ & $20(57.14 \%)$ & $11(52.38 \%)$ & $20(83.33 \%)$ & \\
\hline \multirow[t]{2}{*}{ Gender } & M & $27(77.14 \%)$ & $12(57.14 \%)$ & $15(62.50 \%)$ & \multirow[t]{2}{*}{ *NS } \\
\hline & $\mathrm{K}$ & $8(22.86 \%)$ & $9(42.86 \%)$ & $9(37.50 \%)$ & \\
\hline \multirow[t]{3}{*}{ Location } & upper $1 / 3$ & $2(5.71 \%)$ & $0(0.00 \%)$ & $4(16.67 \%)$ & \multirow[t]{3}{*}{0.02} \\
\hline & middle $1 / 3$ & $16(45.71 \%)$ & $13(61.90 \%)$ & $5(20.83 \%)$ & \\
\hline & lower $1 / 3$ & $17(48.57 \%)$ & $8(38.10 \%)$ & $15(62.50 \%)$ & \\
\hline \multirow[t]{3}{*}{ Invasion depth } & mucosa & $5(14.29 \%)$ & $5(23.81 \%)$ & $1(4.17 \%)$ & \multirow[t]{3}{*}{ *NS } \\
\hline & muscular coat & $8(22.86 \%)$ & $3(14.29 \%)$ & $5(20.83 \%)$ & \\
\hline & serosa & $22(62.86 \%)$ & $13(61.90 \%)$ & $18(75.00 \%)$ & \\
\hline \multirow{4}{*}{$\begin{array}{l}\text { Bormann's } \\
\text { classification }\end{array}$} & I & $3(8.57 \%)$ & $2(9.52 \%)$ & $2(8.33 \%)$ & \multirow[t]{4}{*}{${ }^{*} \mathrm{NS}$} \\
\hline & II & $9(25.71 \%)$ & $5(23.81 \%)$ & $5(20.83 \%)$ & \\
\hline & III & $17(48.57 \%)$ & $11(52.38 \%)$ & $14(58.33 \%)$ & \\
\hline & IV & $6(17.14 \%)$ & $3(14.29 \%)$ & $3(12.50 \%)$ & \\
\hline \multirow[t]{2}{*}{ Lauren's classification } & intestinal type & $26(74.29 \%)$ & $11(52.38 \%)$ & $18(75.00 \%)$ & \multirow[t]{2}{*}{ *NS } \\
\hline & diffuse type & $9(25.71 \%)$ & $10(47.62 \%)$ & $6(25.00 \%)$ & \\
\hline \multirow{2}{*}{$\begin{array}{l}\text { Histological } \\
\text { differentiation }\end{array}$} & $\mathrm{G} 2$ & $16(45.71 \%)$ & $9(42.86 \%)$ & $14(58.33 \%)$ & \multirow[t]{2}{*}{${ }^{*} \mathrm{NS}$} \\
\hline & G3 & $19(54.29 \%)$ & $12(57.14 \%)$ & $10(41.67 \%)$ & \\
\hline \multirow[t]{4}{*}{ Helicobacter pylori } & 0 & $16(45.72 \%)$ & $7(33.33 \%)$ & $14(58.33 \%)$ & \multirow[t]{4}{*}{ *NS } \\
\hline & 1 & $4(11.43 \%)$ & $1(4.7 \%)$ & $2(8.33 \%)$ & \\
\hline & 2 & $5(14.28 \%)$ & $4(19.05 \%)$ & $3(12.5 \%)$ & \\
\hline & 3 & $10(28.57 \%)$ & $9(42.86 \%)$ & $5(20.84 \%)$ & \\
\hline \multirow[t]{3}{*}{$\mathrm{pN}$} & 0 & $22(62.86 \%)$ & $17(80.95 \%)$ & $18(75.00)$ & \multirow[t]{3}{*}{ *NS } \\
\hline & 1 & $9(25.71 \%)$ & $2(9.52 \%)$ & $4(16.67 \%)$ & \\
\hline & 2 & $4(11.43 \%)$ & $2(9.52 \%)$ & $2(8.33 \%)$ & \\
\hline
\end{tabular}

*NS - not statistically significant

We found no statistically significant correlation between the expression of Fhit protein in advanced gastric carcinoma and such clinicopathological parameters as patients' gender, depth of invasion in the gastric wall or histological differentiation grade. Similarly, we found no relationship between the protein expression and Lauren's and Borman's classifications. These data are consistent with the findings obtained by other researchers $[13,14,15]$. Capuzzi et al. [13] found no correlation between Fhit protein expression and Lauren's classification or the rest of parameters. Also tumour invasiveness did not correlate significantly with Fhit protein expression. However, they noted a significant negative correlation of Fhit protein expression with tumour stage at the time of diagnosis and with histological differentiation grade. More advanced tumours with higher differentiation grade more frequently showed lack of Fhit protein expression [15]. Also Naguchi et al. found no relationship between Fhit protein expression and major prognostic factors such as $\mathrm{pT}, \mathrm{pN}$, infiltration via veins or differentiation grade [11]. On the other hand, Rocco et al. [9] demonstrated a decrease in Fhit expression or its lack in most gastric adenocarcinomas, with a statistically significant correlation in the diffuse type, low differentiation grade and advanced stage. Changes in 
Table 2. Correlation between Fhit protein expression in lymph node and chosen clinicopathological parameters in gastric carcinoma.

\begin{tabular}{|c|c|c|c|c|c|}
\hline \multirow{2}{*}{\multicolumn{2}{|c|}{ Parameters }} & \multicolumn{4}{|c|}{ Fhit protein expression in lymph node } \\
\hline & & \multirow{2}{*}{$\begin{array}{c}0(\mathrm{n}=1) \\
0(0.00 \%)\end{array}$} & \multirow{2}{*}{$\frac{1(\mathrm{n}=12)}{6(50.00 \%)}$} & \multirow{2}{*}{$\frac{2(\mathrm{n}=2)}{0(0.00 \%)}$} & $\mathrm{p}$ \\
\hline Age & $<=60$ & & & & \multirow{2}{*}{ *NS } \\
\hline & $>60$ & $1(100.00 \%)$ & $6(50.00 \%)$ & $2(100.00 \%)$ & \\
\hline \multirow[t]{2}{*}{ Gender } & M & $0(0.00 \%)$ & $7(58.33 \%)$ & $2(100.00 \%)$ & \multirow{2}{*}{ *NS } \\
\hline & $\mathrm{K}$ & $1(100.00 \%)$ & $5(41.67 \%)$ & $0(0.00 \%)$ & \\
\hline \multirow[t]{3}{*}{ Location } & upper $1 / 3$ & $0(0.00 \%)$ & $1(8.33 \%)$ & $0(0.00 \%)$ & \multirow{3}{*}{$*$ NS } \\
\hline & middle $1 / 3$ & $1(100.00 \%)$ & $7(58.33 \%)$ & $1(50.00 \%)$ & \\
\hline & lower $1 / 3$ & $0(0.00 \%)$ & $4(33.33 \%)$ & $1(50.00 \%)$ & \\
\hline \multirow[t]{3}{*}{ Invasion depth } & mucosa & $0(0.00 \%)$ & $0(0.00 \%)$ & $0(0.00 \%)$ & \multirow{3}{*}{${ }^{*} \mathrm{NS}$} \\
\hline & muscular coat & $0(0.00 \%)$ & $1(8.33 \%)$ & $0(0.00 \%)$ & \\
\hline & scrosa & $1(100.00 \%)$ & $11(91.67 \%)$ & $2(100.00 \%)$ & \\
\hline \multirow{4}{*}{$\begin{array}{l}\text { Bormann's } \\
\text { classification }\end{array}$} & I & $0(0.00 \%)$ & $0(0.00 \%)$ & $0(0.00 \%)$ & \multirow{4}{*}{$* \mathrm{NS}$} \\
\hline & II & $0(0.00 \%)$ & $3(25.00 \%)$ & $0(0.00 \%)$ & \\
\hline & III & $1(100.00 \%)$ & $6(50.00 \%)$ & $0(0.00 \%)$ & \\
\hline & IV & $0(0.00 \%)$ & $3(25.00 \%)$ & $2(100.00 \%)$ & \\
\hline \multirow{2}{*}{$\begin{array}{l}\text { Lauren's } \\
\text { classification }\end{array}$} & intestinal type & $1(100.00 \%)$ & $7(58.33 \%)$ & $1(50.00 \%)$ & \multirow{2}{*}{ *NS } \\
\hline & diffuse type & $0(0.00 \%)$ & $5(41.67 \%)$ & $1(50.00 \%)$ & \\
\hline \multirow{2}{*}{$\begin{array}{l}\text { Histological } \\
\text { differentiation }\end{array}$} & G2 & $1(100.00 \%)$ & $4(33.33 \%)$ & $0(0.00 \%)$ & \multirow[t]{2}{*}{$* \mathrm{NS}$} \\
\hline & G3 & $0(0.00 \%)$ & $8(66.67 \%)$ & $2(100.00 \%)$ & \\
\hline \multirow[t]{4}{*}{$\mathrm{pN}$} & 0 & $0(0.00 \%)$ & $6(50.00 \%)$ & $0(0.00 \%)$ & \multirow{4}{*}{ *NS } \\
\hline & 1 & $0(0.00 \%)$ & $0(0.00 \%)$ & $0(0.00 \%)$ & \\
\hline & 2 & $1(100.00 \%)$ & $2(16.67 \%)$ & $1(50.00 \%)$ & \\
\hline & 3 & $0(0.00 \%)$ & $4(33.33 \%)$ & $\mathrm{l}(50.00 \%)$ & \\
\hline \multirow[t]{4}{*}{ Helicobacter pylori } & 0 & $0(0.00 \%)$ & $6(50.00 \%)$ & $0(0.00 \%)$ & \multirow{4}{*}{${ }^{*} \mathrm{NS}$} \\
\hline & 1 & $0(0.00 \%)$ & $0(0.00 \%)$ & $0(0.00 \%)$ & \\
\hline & 2 & $1(100.00 \%)$ & $2(16.67 \%)$ & $1(50.00 \%)$ & \\
\hline & 3 & $0(0.00 \%)$ & $4(33.33 \%)$ & $\mathrm{l}(50.00 \%)$ & \\
\hline
\end{tabular}

*NS - not statistically significant

Table 3. Correlation of Fhit protein expression in lymph node with metastasis and in the main mass of tumour in advanced gastric carcinoma.

\begin{tabular}{|c|c|c|c|c|}
\hline \multirow{2}{*}{ Fhit protein expression in lymph node } & \multicolumn{3}{|c|}{ Fhit protein expression in tumour } \\
\cline { 2 - 5 } & $0(\mathrm{n}=9)$ & $1(\mathrm{n}=3)$ & $2(\mathrm{n}=3)$ & $0(0.00 \%)$ \\
\hline 0 & $1(11.11 \%)$ & $0(0.00 \%)$ & $3(100.00 \%)$ \\
\hline 1 & $6(66.67 \%)$ & $3(100.00 \%)$ & $0(0.00 \%)$ \\
\hline 2 & $2(22.22 \%)$ & $0(0.00 \%)$ & NS \\
\hline
\end{tabular}

*NS - not statistically significant 
Fig. 1. Correlation of Fhit protein expression in the main mass of tumour with survival time of patients with advanced gastric carcinomas $(\mathrm{p}=0.26)$.

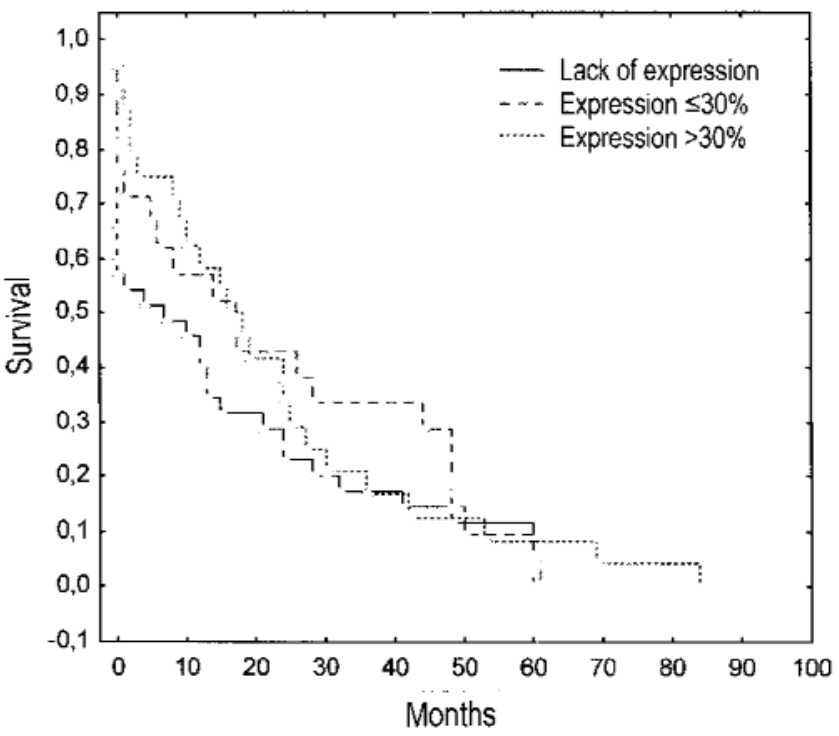

the FHIT gene were directly correlated with a lack of Fhit expression, and thus the immunohistochemically examined protein expression appears to be a sensitive marker of changes in the FHIT gene [9].

A statistically significant correlation was observed between lack or reduction in the expression of Fhit protein expression and lymph node involvement. No relationship was found between Fhit expression and advancement stage and histological differentiation grade [8]. We did not observe any statistically significant correlation between the expression of Fhit protein in the main mass of tumour and the presence of lymph node involvement. Among 80 cases assessed in our study, metastases to local lymph nodes were present in 23 . The affected lymph nodes most frequently showed lack of Fhit protein expression (13 cases), four lymph nodes displayed Fhit expression in $\leq 30 \%$ and six in $>30 \%$ of tumour cells.

A comparison of a lack of heterozygosity (LOH) within the FHIT locus with histopathomorphological features revealed no statistically significant differences between the histological type and type of growth pattern according to Lauren's classification and WHO classification [16]. An allelic loss of the FHIT gene, depending on invasion depth (pT), was observed in $25 \%$ of all the early gastric cancers. However, no significant correlation was found between $\mathrm{LOH}$ frequencies in early gastric cancers (pT1) and advanced gastric cancers (pT2- pT4). Moreover, no relationship was observed between LOH of the FHIT gene and lymph node involvement $(\mathrm{pN})$, differentiation grade or invasion through veins. Moreover, LOH of the FHIT gene did not affect prognosis within various groups of patients according to Lauren's classification or impor- tant prognostic parameters such as invasion depth (pT) and lymph node involvement $(\mathrm{pN})[11,14]$.

We found a statistically significant relationship between tumour Fhit protein expression and patients' age. We observed a lack or reduction in the expression mainly in elderly patients (over 60). Similarly, strong Fhit expression was also noted in patients aged $>60$ (20 cases) as compared to patients in the age range $\leq 60$ years (4 cases).

A statistically significant correlation was found between the expression of Fhit protein in the neoplastic tissue and tumour location in the stomach. We found the absence of the expression or its reduction in patients with lesions located in the middle $1 / 3$ part of the stomach. Strong expression of the protein was noted mainly in patients with a lesion located in the lower $1 / 3$ of the stomach or throughout this organ.

Skopelitou et al. [17] demonstrated a lack or reduction in the expression of Fhit protein in the inflammation of gastric mucosa associated with Helicobacter pylori infection. Negative immunohistochemical staining, similar in chronic gastric mucosa inflammation and in gastric adenocarcinomas, was found to strongly correlate with $H$. pylori infection and with dysplasia, but not with intestinal metaplasia or $H$. pylori activation grade. Moreover, these investigators showed a correlation between lack or reduction in Fhit protein expression and dysplasia degree or neoplastic progression. Similarly, Stec-Michalska et al. [18] reported a relationship between a decrease in Fhit expression and the presence of dysplasia or family history of gastric carcinoma, especially in association with Helicobacter pylori. In our study, the lack or reduction in Fhit protein expression was most common in patients with high degree of $H$. pylori infection. These data, however, were not statistically significant.

In our study, no correlation was noted between the lack of Fhit protein expression in the main mass of tumour and survival time. Patients with strong immunohistochemical reaction in tumour $(>30 \%$ of the cells) were found to live much longer after surgery as compared to those without Fhit expression in cancer tissue or with the expression observed in less than $30 \%$ of tumour cells. This difference was significant (approximately 25 months).

This finding seems to suggest that a lack or reduction in Fhit protein expression in tumour can be an unfavourable prognostic factor for patients with advanced gastric cancers. However, the differences were not statistically significant.

Similar correlations were observed by Capuzzi et al. [13]. They found a significant correlation between Fhit protein expression and survival time of patients with gastric cancer. Patients with tumour without Fhit expression died much earlier as compared to those showing positive reaction to Fhit. Moreover, 


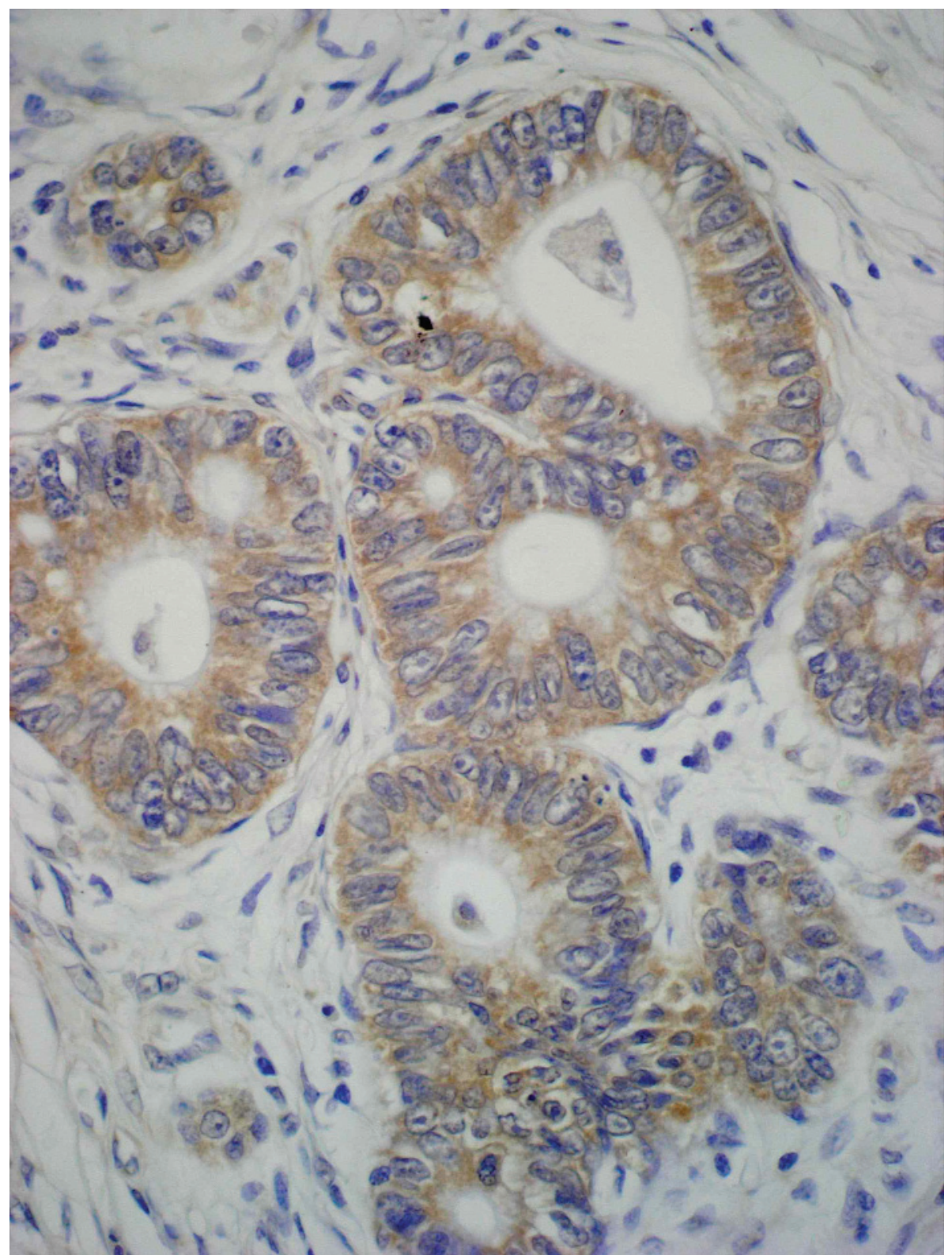

Fig. 2. Fhit protein expression in gastric carcinoma (original magnification $\times 40$ ) the researchers demonstrated a relationship of tumour advancement grade with survival time but not with histological differentiation grade. Reduction in Fhit protein expression was associated with shorter survival time, irrespective of tumour histological differentiation grade. They also observed a correlation between a reduction in Fhit expression in more advanced tumours and shorter survival time. Higher stage of tumour advancement may thus indicate unfavourable prognosis.

Our findings may suggest that a lack of Fhit protein expression can be a favourable prognostic factor in patients with advanced gastric cancer. However, these data were not statistically significantly correlated.

\section{References}

[ 1] Kelley JR and Duggon JM. Gastric cancer epidemiology and risk factors. Commentary. J Clin Epidemiology. 2003;56:1-9.

[2] Wojciechowska U, Didkowska J, Tarkowski W and Zatoński W. Nowotwory złośliwe w Polsce w 2003 roku. Centrum Onkologii-Instytut im. Marii Skłodowskiej-Curie. Warszawa 2005.

[3] Chen J, Chen M, Röcken Ch, Götze, Malfertheiner P and Ebert MPA. Molecular therapy of gastric cancer. Cancer Therapy. 2003;1:323-333.

[ 4] Correa P, Ruiz B, Shi TT, Janney A, Sobhan M, Torrado J et al. Helicobacter pylori and nucleolar organizer regions in gastric antral mucoas. Am J Clin Pathol. 1994;101:656-660.

[5] Hibi K, Takahashi T, Yamakawa $\mathrm{K}$ et al. Three distinct regions involved in $3 \mathrm{p}$ deletions in human lung cancer. Oncogene. 1992;7:445-449. 
[ 6] Murhpy GA, Hallday D and McLennan AG. The FHIT tumor suppressor protein regulates the intracellular concentration of diadenosine triphosphatase but not diadenosine tetraphosphate. Cancer Res. 2000;60:2342-234.

[7] Ji L, Fang B, Yen N, Fong K, Minna JD and Roth JA. Induction of apoptosis and ihibiotoin of tumorigenicity and tumor growth by adenowirus Victor- medieted fragilehistidine triad (FHIT) gene overexpression. Cancer Res. 1999;59:33333339.

[ 8] Huebner K and Croce CM. Cancer and the FRAB3B/FHIT fragile locus: it's a HIT. Br J Cancer. 2003; 88:1501-1506.

[9] Rocco A, Schandal L, Chen J, Wang H, Tulassay Z, McNamara D, Malfertheiner P and Ebert MP. Loss of FHIT protein expression correlates with disease progression and poor differentiation in gastric cancer. $J$ Cancer Res Clin Oncol. 2003;129:84-88.

[10] Naylor SL, Johnson BE, Minna JD et al. Los sof heterozygosity of chromosome $3 p$ markers in small cell lung cancer. Nature. 1987;329:451-454.

[11] Naguchi T, Müller W, Witz HCh, Willers R and Gabbert HE. FHIT gene in gastric cancer: association with tumour progression and prognosis. J Pathol. 1999;188:378-381.

[12] Pekarsky Y, Zanesi N, Palamarchuk A, Huebner K and Croce CM. FHIT: from gene Discovery to cancer treatment and prevention. Oncology. 2002;3:748-754.

[13] Capuzzi D, Santoro E, Hauck WW, Kovatich AJ, Rosato FE, Baffa R, Huebner K and McCue PA. Fhit expression in gastric adenocarcinoma- correlation with disease stage and survival. Am Cancer Society. 2000; 88:24-34.
[14] Kawaguchi K, Yashima K, Koda M, Tsutsumi A, Kitajka S, Andach H, Hosoda A, Kishimoto Y, Shiota G and Murawaki Y. Fhit expression in human gastric adenomas and intramucosal carcinoma: correlation with Mlh I expression and gastric phenotype. Br J Cancer. 2004;90:672-677.

[15] Lee SH, Kim WH,Kim HK, WooKM, Nam HS,Kim HS, Kim $\mathrm{JG}$ and Cho MH. Altered expression of the fragile histidine triad gene in primary gastric adenocarcinomas. Bioch Bioph Res Comm. 2001;284:850- 855.

[16] Huiping C, Kristjansdottir S, Bergthorsson JT, Jonasson JG, Magnusson J, Egilsson V and Ingvarsson S. High frequency of LOH, MSI and abnormal expression of FHIT in gastric cancer. Eur J Cancer. 2002;38:728-735.

[17] Skopelitou AS, Mitselou A, Katsanos KH, Alexopoulou V and Tsianos EV. Immunohistochemical expression of Fhit protein in Helicobacter pylori related chronic gastritis, gastric precancerous lesions and gastric carcinoma: correlation with conventional clinicopathologic parameters. Eur J Gastroenterol Hepatol. 2003;15:515-523.

[18] Stec-Michalska K, Antoszczyk S, Klupnicka G and Nawrot B. Los sof FHIT expression in gastric mucosa of patients with family history of gastric cancer and Helicobacter pylori infection. World J Gastroenterol. 2005;7:17-21.

Submitted: 30 November, 2008 Accepted after reviews: 27 December 2009 